\title{
Does increasing the spatial resolution in dynamical downscaling impact climate change projection of Indian summer monsoon, population and GDP?
}

Jayasankar C B ( $\sim$ cbjayasankar@gmail.com )

Center for Study of Science, Technology and Policy https://orcid.org/0000-0001-5926-6653

\section{Rajendran $\mathrm{K}$}

CSIR Fourth Paradigm Institute (CSIR-4PI), NAL Belur Campus3CSIR Fourth Paradigm Institute (CSIR4PI), NAL Belur Campus

\section{Sajani Surendran}

CSIR Fourth Paradigm Institute (CSIR-4PI), NAL Belur Campus

\section{Research Article}

Keywords: Indian Summer Monsoon Rainfall, Dynamical Downscaling, Regional Climate Model, CORDEX South Asia, Socio-economic Projections, Shared Socio-economic Pathways (SSPs)

Posted Date: April 13th, 2021

DOl: https://doi.org/10.21203/rs.3.rs-390689/v1

License: (9) This work is licensed under a Creative Commons Attribution 4.0 International License. Read Full License 


\section{Abstract}

High-resolution regional climate model (RCM) simulations are found to be very useful in deriving realistic climate change projection information. This study uses high-resolution dynamical downscaling framework (CCSM4-WRF) for India. To delineate the advantage of high resolution, we compared the results of 9-km resolution CCSM4-WRF simulations against the 50-km resolution RCM simulations under Coordinated Regional Climate Downscaling Experiment-South Asia (CORDEX-SA) programme. Quantitative estimations show that majority of CORDEX-SA models exhibit large dry bias ( $<-4 \mathrm{~mm} /$ day) and low pattern correlation coefficient (PCC) over the Western Ghats (WG). Mean climatology of Indian summer monsoon (ISM) rainfall simulated by high-resolution CCSM4-WRF outperforms the CORDEX-SA RCMs with low negative biases ( $1 \mathrm{~mm} /$ day) and high PCC $(\geq 0.755)$. This skill of CCSM4-WRF provides better confidence in its future projection at local scale. CCSM4-WRF projects future intensification of monsoon rainfall over most parts of India and reduction over southern WG, which is consistent with recent observed trends, but none of the CORDEX-SA RCMs could simulate this rainfall reduction. For allIndia rainfall, ensemble mean of CORDEX-SA models projects an increase by $1.3 \pm 0.9 \mathrm{~mm} /$ day and CCSM4-WRF projects $0.67 \mathrm{~mm} /$ day. Projected changes in socioeconomic variables such as population and gross domestic product (GDP) exhibit future enhancement over most parts of India but with spatial heterogeneity. Shared Socioeconomic Pathways scenarios show pronounced future population growth over Indian coastal areas, and large enhancement in productivity over urban areas. Therefore, climate change projection information of ISM rainfall, together with enhanced future population and GDP, is useful for taking necessary steps for adaptation and mitigation in a sustainable manner.

\section{Introduction}

India is among the monsoon-dominant tropical countries, with majority of the rural population still dependent on agriculture. During the monsoon, rainfall received over the country has greater socioeconomic importance than other meteorological variables. The agricultural production and the country's economy, through gross domestic product (GDP), are intertwined on the stability of monsoon rainfall (Krishna Kumar et al. 2004; Gadgil and Gadgil 2006). The summer monsoon season (June to September) is the major rainy season in India, during which the region receives a mean rainfall of 852 $\mathrm{mm}(80 \%$ of annual rainfall, Parthasarathy et al. 1994) with $10 \%$ coefficient of variation (i.e. standard deviation divided by mean). During the summer monsoon, orographic influence is prominent in the distribution of rainfall over India, especially the west coast and northeast India. This is because the prevailing moisture-laden south-west monsoon winds blow almost at right angle to the Western Ghats (WG) and the Khasi-Jaintia hills (Rao 1976). Global warming plays a decisive role in the strength and variability of the future Indian summer monsoon (ISM) rainfall. Hence, even minor changes in the country's rainfall variability (in spatial or temporal scale) due to global warming can have an immense impact on water resources and agricultural production (Gadgil 1995; Webster et al. 1998). This, in turn, affects food security, livelihood of farmers, and economy of the country. 
We know that the most important feature of ISM for livelihoods is rainfall occurring during the season. Most of the state-of-the-art Coupled General Circulation Models (CGCMs) face challenges in simulating ISM rainfall (Gadgil and Sajani 1998). After identifying the physically consistent groups of Coupled Model Intercomparison Project Phase 5 (CMIP5) models with the highest reliability, Jayasankar et al. (2015) derived the future projections of Indian summer monsoon rainfall and variability. Recently, the state-of-the-art Coupled Model Intercomparison Project Phase 6 (CMIP6) models are being used to derive the future projections summer monsoon rainfall over India (Moon and Ha 2020; Almazroui et al. 2020). The global monsoon strength and precipitation are better simulated by CMIP6 models than by CMIP5 (Wang et al. 2020). In a study, Rajendran et al. (2021) found that the multimodel ensemble mean (MME) of 61 CMIP6 models is better than that of CMIP5 models in simulating mean and variability of Indian summer monsoon rainfall over India. The present-day simulations of several CMIP6 models capture the spatio-temporal patterns of the summer monsoon rainfall over India, especially over the Western Ghats and northeast foothills of Himalayas (Gusain et al. 2019, Rajendran et al. 2021). However, many of them are having horizontal resolution of about 100 kilometers or more. Due to which they face difficulties in resolving the sharp variation of WG orography of the west coast region and fail to capture observed regional characteristics (Mishra et al. 2018). It is to be noted that CMIP5/CMIP6 models still project uniform increase in ISMR over India (Jayasankar et al. 2015; Moon and Ha 2020; Almazroui et al. 2020). Giorgi and Marinucci (1996) found that precipitation amounts are highly sensitive to the resolution of the climate model. Also, increase in resolution results in improvement in the representation of the orography and associated precipitation, especially over the WG region (Rajendran et al. 2012). High-resolution simulations are found to be very useful to derive realistic climate change information at regional scale, which is crucial for climate change impact assessments.

The high-resolution was crucial not only for realistic simulation of spatial heterogeneity of mean summer monsoon, but also for attaining useful climate change projections of its mean and extremes (Rajendran et al. 2013). Under the future warming scenario, the high-resolution $(20-\mathrm{km})$ model projects an increase in rainfall over interior India, but projects significant orographic rainfall reduction over the west coast of India at the end of the 21st century (Rajendran et al. 2012, 2013). The coarse resolution CMIP5 model could not simulate the observed decreasing trend in present-day monsoon rainfall over the WG region, but this trend is well simulated in high-resolution GCMs (Rajendran et al. 2012). Hence, to study the regional scale characteristics, it is essential to use a sufficiently high-resolution model. To overcome the difficulties caused by inadequate horizontal resolution and to study the finer-scale climate features, an alternative way is to downscale those GCMs by using a high-resolution regional climate model (RCM, Wang et al. 2004; IPCC 2013). This requires a high-resolution RCM driven by the initial and lateral boundary conditions from the global GCM (Dickinson et al. 1989; Giorgi et al. 1990; Jayasankar et al. 2018; Jayasankar 2019). There are several studies, which attempted to simulate the Indian summer monsoon and its seasonal variability using RCMs through dynamical downscaling technique (Bhaskaran et al. 1996; Dash et al. 2006; Ratnam et al. 2009). RCMs were also utilized as an useful tool to study the high-resolution climate change projections over India (Kumar et al. 2006; Mishra et al. 2014; Dash et al. 2015). 
To evaluate the performance of various RCMs for regional climate projections at high-resolution, World Climate Research Programme (WCRP) initiated the Coordinated Regional Climate Downscaling Experiments (CORDEX) programme (Giorgi et al. 2009). This is a framework for downscaled climate change projections from the CMIP5 GCMs. CORDEX - South Asia (SA) domain covers the Indian region with RCMs are having a spatial resolution of $0.44^{\circ}(\sim 50-\mathrm{km})$. The inability to represent realistic spatial distribution of the summer monsoon rainfall at regional scale by the coarse resolution CMIP5 models is considerably rectified through the dynamical downscaling with most suitable physics schemes and domain set up (Jayasankar et al. 2018). These high-resolution downscaled simulations can be effectively used to understand the climate change projection at regional scale. However, studies using CORDEX-SA models show that many models exhibit lower skill in simulating the mean, variability and extremes of ISM (Singh et al. 2017). Mishra et al. (2014) analyzed these models in the context of precipitation extremes and found that few models showed improvement in simulating the rainfall extremes over India than its parent GCM. Few studies shows that the CORDEX-SA models highly overestimate the mean precipitation over the high altitude (e.g. Himalayas) regions (Sanjay et al. 2017a; Ghimire et al. 2018). Choudhary et al. (2018) found a notable dry rainfall bias over most of India, especially over central India, from the thorough evaluation of present-day summer monsoon simulations using 11 CORDEX-SA models. However, when comparing the RCM to its parent GCM, few other studies found an improvement in the mean climate and extreme events over South Asia (Gu et al. 2012; Hassan et al. 2015). A detailed analysis of the mean summer monsoon climatology over India revealed that downscaling may not always improve the seasonal averages, and it strongly depends on the choice of the RCM and the driving GCM (Sanjay et al. 2017b). However, in a study, Jayasankar et al. (2018) showed that employing sufficiently high-resolution RCM driven by bias-corrected boundary datasets with a suitable configuration results in realistic present-day ISM simulation as well as useful regional climate change projection.

The Weather Research and Forecasting (WRF) - Advanced Research WRF (WRF-ARW) model is considered as the next generation RCM, which is the most suitable and potentially useful tool for highresolution regional climate modelling (e.g., Paul et al. 2018) as well as dynamical downscaling (e.g., Lo et al. 2008; Jayasankar et al. 2018). Hence, a high-resolution dynamical downscaling framework for the Indian region is implemented by Jayasankar et al. (2018), in which a high-resolution RCM (i.e., WRF-ARW) is one-way nested into bias-corrected NCAR-CCSM4-one of the CMIP5 GCMs (hereafter referred to as CCSM4-WRF). This CCSM4-WRF shows high fidelity in capturing important physical and dynamical characteristics of present-day ISM and extreme rainfall events, particularly recent trends in ISM rainfall over southern WG as observed (e.g., Rajendran et al. 2012). Its skill in simulating the present-day ISM provides better confidence in its future projection at the regional scale. Using this, climate change projections of ISM under the IPCC Representative Concentration Pathways 8.5 (RCP8.5) scenario (which is a worst-case scenario) was obtained by Jayasankar et al. (2018). Though the WRF-ARW has been included as one of the RCMs in the CORDEX-SA programme, but dynamical downscaled simulations using WRF-ARW are not available yet for the CORDEX-SA domain. Therefore, it is important to assess the performance of WRF-ARW as high-resolution RCM over the SA domain. In this study, after validating the CCSM4-WRF with observational datasets, we compared the results of our 9-km CCSM4-WRF simulations 
over Indian region with the 50-km resolution dynamically downscaled simulations under the CORDEX-SA programme.

The scenarios are found to be the integral part of the climate change research. Similar to RCP forcing scenarios, a set of socioeconomic scenarios called Shared Socioeconomic Pathways (SSPs) was implemented (Kriegler et al. 2012; O'Neill et al. 2014; O'Neill et al. 2017); this is considered as a reference scenario for impact assessments, adaptation and mitigation. The RCP scenarios are described based on the overall warming that may occur by the end of the century as a result of GHG emissions, while SSPS look at the likelihood of potential emissions reductions. There are five SSP scenarios (SSP 1 to 5) classified in terms of socioeconomic challenges to adaptation (abscissa) and mitigation (ordinate). These five SSPs scenarios provide insights into how various rates of climate change mitigation could be accomplished by integrating RCP mitigation goals with SSPs. In these scenarios, SSP1 (good sustainability) stands for low mitigation and adaptation, SSP2 (middle of the road) stands for moderate, SSP3 (regional rivalry, unsustainable) for high mitigation and adaptation, SSP4 (increasing inequality) is dominant in adaptation challenges, and SSP5 (fossil-fueled development) is dominant in mitigation challenges (Fig. 1 of O'Neill et al. 2014). Such scenarios are used to describe how the choices of society can impact future GHG emissions. These set of SSPs can also be used to quantitatively estimate the projected changes of population, economic growth, and land use. Different studies use these scenarios for various purposes; for instance, Wiebe et al. (2015) used SSPs to analyze the effect of climate change on agricultural development and markets. In this paper, we tried to relate the projected changes in ISM rainfall and the future changes in the population and GDP under three socioeconomic pathways (SSP1, SSP2, and SSP3).

The major objective of this study is to (a) delineate the advantage of high resolution to study the regional scale climate change projection of ISM rainfall by comparing the high-resolution (9-km) dynamically downscaled CCM4-WRF simulation with 50-km resolution CORDEX-SA model simulations, (b) quantify the projected ISM rainfall changes over different homogeneous zones of India, with possible uncertainty; and c) discuss application utility of the future changes in ISM rainfall along with the projected changes of socioeconomic variable such as population and GDP over India, derived from SSP scenarios.

\section{Models, Simulations And Data}

\subsection{CORDEX-SA models}

The dynamically downscaled climate simulations of the CORDEX framework for the SA region at $\sim 50-\mathrm{km}$ resolution are available for the scientific research community. These simulations have been derived from the state-of-the-art coupled GCMs participated in Coupled Model Intercomparison Project Phase 5 (CMIP5). Two RCMs-the Regional Climate Model system version 4 (RegCM4) and Rossby Centre regional Atmospheric model (RCA4)-simulations from the CORDEX-SA experiments are utilized in this study. Each model uses different physics, dynamics, and grid structure but with a common horizontal resolution of 50-km, which cover entire SA region. The historical runs of 14 CORDEX-SA models for a 10- 
year period from 1981 to 1990 (present-day) and their RCP8.5 runs for projections (2090-2099) are obtained for the present study. These datasets were acquired from the ESGF data portal (https://esgfdata.dkrz.de/search/cordex-dkrz/). The future projections' datasets used are the simulations forced with high greenhouse gas (GHG) emission of IPCC RCP8.5 scenario. The prescribed yearly changing GHG concentrations (observed values in the historical period and RCP8.5 scenario in the future) are same for both the RCMs and the CMIP5 CGCMs. The basic details of the CORDEX-SA experiments (RCMs and their driving CGCMs) are provided in Table 1. We used monthly model outputs for the present analysis.

\subsection{CCSM4-WRF model}

The high-resolution dynamically downscaled simulations are obtained using non-hydrostatic WRF-ARW. The present study has been carried out using same configuration of WRF-ARW as described in Jayasankar et al. (2018). In this configuration, the physics schemes included the Community Atmospheric Model (CAM) for atmospheric longwave and shortwave radiation, WRF Single-Moment 6Class Microphysics Scheme (WSM6), the Yonsei University (YSU) scheme for the planetary boundary layer turbulence, and the unified Noah land surface scheme. For realistic representation of ISM rainfall, we chose Kain-Fritsch (KF) scheme (e.g., Jayasankar et al. 2018, Jayasankar 2019) for deep convection. To eliminate the spurious influence of boundaries on large-scale circulation, we applied spectral nudging (Miguez-Macho et al. 2004) of the long waves longer than 1,100 km to the zonal and meridional winds, potential temperature, and geopotential, at all levels above the boundary layer. This high-resolution RCM was configured with one-way nesting setup with three domains, the horizontal resolutions of which increase inwards, viz., 27-km, 9-km and 3-km and have 29 vertical levels. The innermost domain, with 3$\mathrm{km}$ resolution, zoomed over southern west coast of India. This study uses the 9-km resolution (i.e., 2nd domain) RCM simulation which cover the entire Indian landmass. The simulations were carried out for a full year, from 1 January of a year to 1 January of the next year, for a 10-year period from 1981 to 1990 (present-day) as well as in the future (2090-2099). High-resolution (27-km, 9-km and 3-km) RCM simulations are found to computationally expensive therefore we could only use a single RCM/GCM combination and stick to the 10-year simulation in the present-day period and future. RCM is forced with $0.9375^{\circ} \times 1.25^{\circ}$ resolution fields from NCAR-CCSM4 (i.e., CCSM4-WRF), which is one among the most

reliable group of IPCC AR5 models, as identified by Jayasankar et al. (2015). It was found that correcting the mean bias of the parent GCM can help improve the downscaled simulations ( $X u$ and Yang 2012; Bruy'ere et al. 2014). Therefore, the mean bias of the 6-hourly boundary datasets were corrected using ERA-Interim reanalysis. More details on the model, domains, simulations, and the methodology of biascorrecting the NCAR-CCSM4 are given in Jayasankar et al. (2018).

\subsection{Validation Datasets}

To validate simulated present-day summer monsoon rainfall over India by the regional models, we used the India Meteorological Department (IMD) gridded daily rainfall data based on 1,803 stations (Rajeevan et al. 2006) for the period $1981-1990$ at $0.5^{\circ} \times 0.5^{\circ}$ resolution. For the validation of present-day simulations and comparison of the results, all the model simulation datasets were re-gridded to the IMD observation resolution. 


\section{Results And Discussions}

\subsection{Present-day Simulations}

The climatological mean summer monsoon rainfall over India from the IMD observation is shown in Fig. 1. The figure also shows the spatial heterogeneity of the summer monsoon rainfall over India. The major rainfall receiving areas are positioned over (i) the core monsoon zone (CMZ, broad region extending to northwest from the head of the Bay of Bengal around $20^{\circ} \mathrm{N}$ ), (ii) the west coast of Peninsular India and (iii) the northeastern regions (Gadgil and Sajani 1998; Gadgil 2003). The CMZ and WG regions are marked in Fig. 1, and these regions are used to estimate the mean bias and pattern correlation coefficient (PCC), along with all India (Al).

The 20th century simulations of the 14 CORDEX-SA models and their multi-model ensemble mean (MME) are analysed to assess their performance in simulating the present-day mean summer monsoon (June to September, JJAS) rainfall over Indian region. Figure 2 shows the JJAS climatological mean rainfall bias of forcing GCM (i.e., NCAR-CCSM4), high-resolution RCM (i.e., CCSM4-WRF) and the MME of the CORDEXSA models with respect to IMD observation. The bias were estimated using 10-year (1981-1990) climatology for both model and observation. From the pattern correlation coefficient (PCC) of the all-India summer monsoon rainfall, it can be seen that CCMS4-WRF (0.78) outperforms the other two models and is much improved than its parent model (0.63). The PCC is 0.71 for the MME of 14 CORDEX-SA RCMs. From the spatial distribution of mean bias of 14 CORDEX RCMs (shown in Fig. S1), we found that only a few models simulate the spatial heterogeneity of the summer monsoon rainfall over India, with the least bias of 1-2 $\mathrm{mm} /$ day. Though some simulations are improved from its parent GCM, many simulations still suffer from large bias ( $>2 \mathrm{~mm} /$ day). Certain models such as the IPSL-RCA4, CSIRO-RegCM4, CSIRORCA4 and CanESM2-RCA4 show large dry bias (<-2mm/day), which is also found in their parent GCMs (IPSL-CM5A-MR, CSIR-MK3.6 and CanESM2). These RCMs could not simulate the location and intensity of major rainfall-receiving areas such as the orographic rain-belt over the WG and CMZ. In comparison, the mean JJAS rainfall simulated by CCSM4-WRF has less bias and is comparable with the observation.

Further, in Table 2, we quantified the climatological mean summer monsoon rainfall bias and PCC against the IMD observation of WRF-CCSM4, 14 CORDEX-SA models, and its multi-model ensemble mean (MME) over Al, CMZ and WG regions. It clearly shows that though the mean bias over Al or CMZ is low for many models, a majority of the CORDEX-SA models exhibit large dry bias ( $<-4 \mathrm{~mm} /$ day) over the WG region. Many models are unable to capture the north-south oriented WG rainfall maxima, which is clearly reflected in its PCC (<0.5). In comparison, models such as CanESM-RegCM4 and CNRM-RCA4 exhibit lower bias over the WG than other CORDEX-SA models. Their bias and PCC over Al and CMZ region demonstrate their superior skill in simulating the Indian summer monsoon rainfall. This disparity among the precipitation simulated by the RCMs could be associated with their convective parametrization or the bias present in the parent GCMs' large-scale forcing (Choudhary et al. 2018). Further, we estimated the mean bias and the PCC of the multi-model ensemble mean of 14 CORDEX-SA models. It shows a bias of $-1.3 \mathrm{~mm} /$ day and the PCC of 0.72 over Al. However, by considering the simulated rainfall, the 
performance of high-resolution CCSM4-WRF is found to be better than the CORDEX-SA models and its MME. CCSM4-WRF also shows reduced rainfall bias ( -1 mm/day) and high PCC (>0.75) over Al, CMZ and WG. Also, CCSM4-WRF shows high fidelity in capturing important physical and dynamical characteristics of present-day ISM and a detailed discussion about the model performance is described in Jayasankar et al. (2018). They showed that the WG rainfall was well resolved by the RCM when its resolution greater than 27-km. Hence, high horizontal resolution certainly a factor for CCSM4-WRF model's better performance. In addition, the fidelity of the CORDEX-SA models and CCSM4-WRF, in simulating mean summer monsoon rainfall over the WG region is assessed based on the Taylor diagram and is shown in Fig. S2. The PCC between IMD observed and the model simulated rainfall (azimuth location), the normalized standard deviation (radial distance) and the centered root mean square error (RMSE) can be obtained from the Taylor diagram. We could see that only very few CORDEX-SA models were comparable with the observation, but their MME was found to be better. However, the CCSM4-WRF agrees the best with observation in all the three aspects of the Taylor diagram.

Previous studies found that increasing the model's horizontal resolution can incorporate more accurate orography, which results in an improved simulation of orographic rainfall. Even though high resolution is achieved by dynamical downscaling, the CORDEX-SA models still lack fidelity in representing the WG orographic rainfall. The reason for large rainfall bias over WG region by these high-resolution models is not so evident. It is well known that the RCM generally provides high-resolution regional aspects embedded within a coarse resolution parent GCM (Kitoh et al. 2016). Likewise, RCM is highly dependent on the large-scale features of the parent GCM. The strength of the low-level monsoon flow into the Indian region determines the strength of the WG rainfall. In a study, Huang et al. (2019) shows that approximately $60-80 \%$ of CMIP5 models underestimate the strength of low-level monsoon flow.

Therefore, we investigated the low-level monsoon flow simulated by the parent GCMs (shown in Fig. S3). The analysis of the present-day simulation of summer monsoon winds reveals that the strength of the low-level summer monsoon flow into the Indian region is either highly underestimated ( 6 models) or overestimated (4 models) by the corresponding parent GCMs. The underestimation of low-level monsoon flow cause a lack of moisture availability as well as reduced orographic lifting, which in a way contribute to the large dry precipitation bias over the WG region. Overestimation of low-level winds may cause cooling of local SST and which may leads to reduced convection, less cloud cover and less precipitation (Voldoire et al. 2019). Therefore, the low-level monsoon flow bias exist in the parent model can be carried forward to the CORDEX-SA RCM simulations, which could be a reason for their summer monsoon rainfall underestimation.

\subsection{Climate Change Projection of Regional Rainfall}

Under global warming scenario, several climate models project future intensification of ISMR along with increase in surface temperature (Sperber et al. 2013; Jayasankar et al. 2015; Moon and Ha 2020; Almazroui et al. 2020). We analyzed the spatial pattern of the projected changes in mean ISM rainfall by the CORDEX-SA models and CCSM4-WRF. The projected change in mean JJAS rainfall by NCAR-CCSM4, CCSM4-WRF and the MME of 14 CORDEX-SA model is shown in Fig. 3. NCAR-CCSM4 projects increase in 
rainfall over majority of the grid-points in India. For the CORDEX-SA models, we estimated the model agreements in the sign of projected change at each grid point, which is indicated by different symbols. A majority of CORDEX-SA models show future intensification of rainfall (as can be seen in Fig. S4) and comparatively high projected change over the southern WG region (14 models agree on this). Interestingly, a few models show future reduction over majority of the Indian grid points, especially over the CMZ (e.g. GFDL-RegCM4, MPI-RegCM4 and MPI-RCA4). On the other hand, CCSM4-WRF projects future intensification of JJAS rainfall over most parts of India and significant future reduction of rainfall over the southern WG. A strong increase in rainfall is projected over the northern WG region. Moreover, it is important to note that this future reduction in the summer monsoon rainfall over southern WG region is in good agreement with recent trends observed over the region (Guhathakurta and Rajeevan 2007;

Rajendran et al. 2012). Even though CORDEX-SA models are at a high resolution, it is still not sufficient to capture the observed recent rainfall trend over the southern WG region.

We quantitatively measured the projected changes of mean summer monsoon rainfall at the end of the 21 st century over homogeneous regions of India, based on the MME of 14 CORDEX-SA models, along with intermodal spread as well as CCSM4-WRF, which are shown in Fig. 4. The projected changes by comparatively skillful CORDEX-SA models (such as CNRM-RCA4 and CanESM2-RegCM4) are also shown in Fig. 4. MME projects an overall rainfall enhancement over all the homogeneous regions but exhibit considerable inter-model spread ( $> \pm 0.88 \mathrm{~mm} /$ day) over most of the regions. The MME of CORDEX-SA models project an increase in the mean ISM rainfall by $1.3 \pm 0.9 \mathrm{~mm} /$ day and CCSM4-WRF projects 0.67 $\mathrm{mm} /$ day over all India (Al). The CORDEX-SA MME mean rainfall projection shows an increase of $2.31 \pm$ 1.51 for peninsular India (PI), $0.99 \pm 1.08$ for west central India (WCI), $0.75 \pm 0.88$ for northwest India (NWI), $1.14 \pm 1.37$ for central northeast India (CNI), $2.11 \pm 1.79$ for northeast India (NEI) and $1.36 \pm 0.94$ for hilly regions (HR). Among these regions, the highest $(>1.5 \mathrm{~mm} /$ day) inter-model spread is found over $\mathrm{PI}$ and NEI. This large spread over PI is also reflected from their disparity in the simulated present-day mean rainfall over WG (i.e., large bias). Better performing CORDEX-SA model CanESM2-RegCM4 projects inconsistent future increase in monsoon rainfall over southern west peninsular India (Fig. S4). It is interesting to note that, the mean rainfall change projected by CCSM4-WRF follows the MME of CORDEXSA models except over PI. Future rainfall enhancement projected by CCSM4-WRF is slightly lower in magnitude than the MME and projected changes are $0.43(\mathrm{PI}), 0.52(\mathrm{WCl}), 0.45(\mathrm{NWI}), 0.63(\mathrm{CNI}), 2.26$ (NEI) and $1.67(\mathrm{HR}) \mathrm{mm} /$ day respectively. Over PI, the projected mean rainfall is less $(0.43 \mathrm{~mm} /$ day), which is due to the southern WG rainfall reduction. In contrast, none of the COREDEX-SA models capture this WG future reduction in rainfall. All models instead project intensification, which results in projection of high rainfall enhancement over $\mathrm{PI}$.

\subsection{Key Mechanisms}

Further we looked into the dominant mechanism for the projected future changed in summer monsoon rainfall over India. It is known that future warming leads to an enhancement in the atmospheric water vapour content. Hence, the projected future changes in atmospheric water vapour content was examined using the CCSM4-WRF simulated precipitable water (Pwat). Figure 5a shows the CCSM4-WRF simulated 
mean summer monsoon precipitable water content $\left(\mathrm{kg} / \mathrm{m}^{2}\right)$ values over Indian grid points against the corresponding surface air temperature $\left(\mathrm{T} 2 \mathrm{~m},{ }^{\circ} \mathrm{K}\right)$ for historical and RCP8.5 scenario. The filled circles represent the respective averaged values over India. Figure 5 a shows clear increase in the future precipitable water (from $43.84 \mathrm{~kg} / \mathrm{m}^{2}$ in present-day to $54.97 \mathrm{~kg} / \mathrm{m}^{2}$ in RCP8.5 scenario) along with the increase in air temperature (from $298.52^{\circ} \mathrm{K}$ to $302.03^{\circ} \mathrm{K}$ ), i.e., an average $3.5^{\circ} \mathrm{K}$ increase in $\mathrm{T} 2 \mathrm{~m}$ leads to an increase of $11.13 \mathrm{~kg} / \mathrm{m}^{2}$ Pwat. However, the necessary variables from CORDEX-SA models were not available at the time of analysis. Based on one CORDEX-SA model's (i.e., REM02009 RCM forced by MPIESM GCM) Pwat, Suman and Maity (2020) found projected future increase in the precipitable water over India under RCP8.5 scenario. Thus, as shown in Fig. 5, an increasing water vapour content under climate change scenario is a key mechanism for enhanced monsoon rainfall over India, is consistent with other studies (e.g., Trenberth et al. 2003).

We have seen that the CCSM4-WRF projects a future reduction in rainfall over southern WG and enhancement in the northern WG region (Fig. 3a). Few studies indicate that the reduction in WG rainfall is attributable to the 'upper-tropospheric warming effect' over the area and it can be clearly seen from the high-resolution model projections (Rajendran et al. 2012; Varghese et al. 2020). Jayasankar et al. (2018) found that this RCM (i.e. CCSM4-WRF) projected significant rainfall reduction (10-20\% of mean) over WG region is due to the 'upper-tropospheric warming effect' which stabilizes the atmosphere (i.e., suppression of rainfall). The projected change (future minus present-day) in large scale monsoon flow is analyzed (here we used 27-km resolution) based on the vertically integrated moisture transport, VIMT (integrated up to $100-\mathrm{hPa}$ ) which is shown in Fig. $5 \mathrm{~b}$. Future strengthening of westerly moisture transport to central Indian region from Arabian Sea resulting in enhanced monsoon rainfall over northern WG and central Indian regions. In comparison, decrease in VIMT with increased northerly/easterly components in moisture transport along the steep mountains causing reduction in convection or precipitation over southern WG region. Our analysis reaffirms that the reduced moisture transport to the southern WG region appears to be the dominant mechanism for future reduction of rainfall and enhanced moisture transport into the northern WG and central India causes future increase in rainfall over the northern WG region.

\subsection{Socioeconomic Projections}

Many studies estimated the future mean and extremes of temperature and precipitation over the Indian region. The projected changes in mean temperature show considerable enhancement over India $\left(\sim 4^{\circ} \mathrm{C}\right.$, Jayasankar 2019), with temperature extremes also found to be increasing on par with the mean temperature. Similarly, we found that CCSM4-WRF projected mean summer monsoon rainfall exhibits an increase over India, but a reduction over southern WG region. Jayasankar et al. (2018) showed that the projected spatial changes in extreme rainfall events are similar to the mean changes. While considering these facts, we explored the projected changes in socioeconomic variables such as population and GDP over India. It was found that due to global warming, along with changes in meteorological variables, there were pronounced changes in socioeconomic variables as well. Therefore, it is pertinent to study the projected changes of socioeconomic variables over the India for taking the necessary steps for sustainability. A scenario framework-Shared Socioeconomic Pathways, or SSPs-has been recently 
developed with international efforts for defining a new set of reference pathways that integrate future radiative forcing scenarios and associated climate changes (Ebi et al. 2014, O'Neil et al. 2014, 2017). These SSPs are accommodated in the climate models participating in the upcoming Sixth Assessment report (AR6) of IPCC. These SSPs can be effectively utilized to find the plausible future projection of socioeconomic variables, which are useful for impact assessment and obtaining adaptation strategies.

The plausible future projection of population and GDP over India is obtained using gridded $\left(0.5^{\circ} \times 0.5^{\circ}\right.$ resolution) population and GDP data of Murakami and Yamagata (2019). These downscaled decadal datasets are available for three SSPs (SSP1, SSP2, and SSP3) from the period 1980 to 2100 . Figure 6 shows the projected change in population and GDP over India by 2100 (with respect to 1990) under three different SSPs. A majority of the grid points over India in all the three SSPs project an increase in population. There is a pronounced future population growth over coastal areas, which is consistent among the SSPs and increases from SSP1 (1-2 million) to SSP3 (> 2 million). Similarly, most major cities of India are expected to experience enhanced population growth, leading to a high population density. In SSP1, the sustainability scenario, many grid points over India show future reduction in population; this reduction changes to enhancement in SSP3. The coastal area population enhancement in future may lead to an exposure to severe causalities due to extreme rainfall events along with future sea-level rise. Also, fresh water demand increases over the coastal areas and cities due to the high population density, leading to increased consumption of ground water.

Over the southern WG, an increase in population coincides with future rainfall reduction, which could lead to higher water demand. The water levels in wells and reservoirs is likely to decline faster because of less rainfall. Many households rely on wells for drinking water. Extreme rainfall spells during certain years can contribute to the seasonal mean (e.g. 2018 Kerala flood). However, these spells do not enhance the ground water level because this water will not percolate into the ground. Instead, the water will likely runoff quickly. Thus, more water scarcity can occur in the future, with a great impact on the communities; we need to mitigate this by formulating proper solutions. For example, fresh water shortage of Chennai city (in Tamil Nadu) due to lack of rainfall in 2019 caused severe problems. Many schools were forced to remain closed; some companies requested their employees to work from home, and in some areas of the city, private tankers that deliver drinking water to neighborhoods began charging double the regular cost. To mitigate Chennai's water woes, the Tamil Nadu government arranged drinking water supply from Vellore district via train. The government also allocated INR 650 million to supply 10 million liters of drinking water per day. This initiative has great significance as they help to reduce the risk due to fresh water shortage. Such potential risk-mitigating measures, including developing and deploying integrated waterways connecting major rivers across states, need to be planned ahead by the state and central governments in future.

The projected change in GDP shows a consistent increase over all the grid points over India but with spatial heterogeneity. Higher productivity is found over urban areas (i.e., from service and industry sectors) and lower productivity in rural areas. SSP1 and SSP2 show enhanced productivity than SSP3 especially over coastal areas and urban areas. The three contributors to Indian GDP are service sector 
(61.5\%, 2016 estimates), industry sector (23\%, 2016 estimates) and agriculture and allied sector (15.5\%, 2016 estimates); these estimates are obtained from The World Factbook (https://www.cia.gov/library/publications/resources/the-world-factbook/fields/214.html). The projected change in GDP is dependent upon population growth, mainly via. labor force available for production. In India, the population growth contributes to the enhancement of productivity. Over southern WG region, water scarcity may affect the productivity of agriculture and allied sectors. However, that loss may be rectified by the enhanced availability of labor and, hence, an increase in productivity.

Further, we quantified the decadal trend of population and GDP over three densely populated Indian cities such as Mumbai, Delhi and Bengaluru (given in Fig. 6 inset). It can be seen that all the three cities show a projected increasing trend in population as well as GDP. Among the three, Bengaluru projects the highest increasing trend in population as well as GDP for all the three SSPs. SSP1 (i.e., scenario of low challenges to mitigation and adaptation) shows highest population trend in all three cities, compared to the other two SSPs. This is because, in SSP1 (low challenges) the worlds shift gradually from the historical patterns to a sustainable conditions. Whereas the SSP2 (medium challenges to adaptation and mitigation) do not shift markedly from the historical conditions, and SSP3 (high challenges to adaptation and mitigation) scenario the population growth is slow. This explicitly says that population growth in the Indian cities may contribute to enhancement in the GDP.

\section{Concluding Remarks}

This study evaluates the high-resolution climate change projection of ISM rainfall under the RCP8.5 scenario derived from dynamically downscaled CCSM4-WRF projections. The results obtained from 9-km resolution CCSM4-WRF simulations are compared against 50-km resolution dynamically downscaled simulations under the CORDEX-SA programme. Before identifying climate change projections, the simulations of CORDEX-SA models and CCSM4-WRF were validated against observation.

Analysis of present-day simulations of CORDEX-SA models shows that only a few models could simulate the spatial heterogeneity of summer monsoon rainfall over India, with least bias (1-2 mm/day). A few simulations are improved upon from its parent general circulation model (GCM), but many simulations still suffer from a large bias (> $2 \mathrm{~mm} /$ day). The models such as IPSL-RCA4, CSIRO-RegCM4, CSIRO-RCA4 and CanESM2-RCA4 show a large dry rainfall bias ( $<-2 \mathrm{~mm} /$ day), which could not simulate the location and intensity of major rainfall areas, especially the orographic rain belt over the WG region. We ascertained that one of the reasons for this could be the underestimation of the strength of low-level summer monsoon flow into the Indian region, by the corresponding parent GCMs. Also, the 50-km horizontal resolution might not be adequate to resolve the WG rainfall, which may be another reason. However, the WG rainfall was well captured by the 9-km resolution CCSM4-WRF model. The mean summer monsoon rainfall simulated by CCSM4-WRF is closer to the observation over the WG region (with bias $<1 \mathrm{~mm} /$ day) than the other 14 CORDEX-SA models investigated here. The quantitative estimations shows that a majority of CORDEX-SA models exhibit large dry bias ( $<-4 \mathrm{~mm} /$ day) and low PCC over the WG region. In comparison, the models such as CanESM-RegCM4 and CNRM-RCA4 exhibit lower bias and 
high PCC over WG than the other CORDEX-SA models. However, by considering the present-day rainfall simulations, the performance of high-resolution CCSM4-WRF is found to be consistent across the regions of interest than the CORDEX-SA models and their MME. It shows a reduced rainfall bias $(\sim-1 \mathrm{~mm} /$ day $)$ and high PCC $(\geq 0.755)$ over Al, CMZ and WG. A majority of the CORDEX-SA models show a future intensification of rainfall. However, a few models show future reduction over a majority of the Indian gridpoints. Meanwhile, CCSM4-WRF projects future intensification of ISM rainfall over most parts of India and a significant future reduction over southern WG region. The MME of CORDEX-SA models project an increase in ISMR by $1.3 \pm 0.9 \mathrm{~mm} /$ day while CCSM4-WRF projects $0.67 \mathrm{~mm} /$ day. The projected change in rainfall for CCSM4-WRF sits well within the realm of uncertainty across the 14 CORDEX-SA models analyzed here. An important process which causes the projected changes in monsoon rainfall could be the enhancement in the atmospheric moisture content. CCSM4-WRF shows an average $3.5^{\circ} \mathrm{K}$ increase in $T 2 \mathrm{~m}$ which leads to an increase of $11.13 \mathrm{~kg} / \mathrm{m}^{2}$ Pwat over India. This study reaffirms that reduced VIMT over southern WG region appears to be the dominant mechanism for future reduction of WG rainfall and strong enhancement in VIMT into the northern WG and central India is the contributing factor for future rainfall enhancement over those regions. The results from this study highlight that a $50-\mathrm{km}$ resolution may not be sufficient to capture important regional aspects, especially over the WG region. Further increase in the resolution of CORDEX-SA models may result in a more realistic representation of the WG orographic rainfall.

It is important to understand the projected changes of the socioeconomic variables, such as population and GDP, because they are important when conducting impact assessment and devising adaptation strategies. Using SSP scenarios, we found a pronounced future population growth over India's coastal areas. It is consistent among SSPs and increases from SSP1 (1-2 million) to SSP3 (>2 million). In addition, the projected change in GDP shows a consistent increase over all the grid-points but with spatial heterogeneity. We also found that urban areas were likely to experience higher productivity than rural areas. The climate change projection of socioeconomic variables over India is also important and requires attention. This needs to be explored further, as it is highly relevant while planning and implementing the steps needed for sustainability.

\section{Declarations}

\section{Acknowledgements}

The first author acknowledges AcSIR for the academic support extended previously. The authors also acknowledge the Research Data Archive (RDA) at the National Center for Atmospheric Research (NCAR), the Computational and Information Systems Laboratory (CISL) for providing the global bias-corrected NCAR-CCSM4 CMIP5 simulation data sets (https://rda.ucar.edu/datasets/ds316.1/). The CORDEX-SA simulations used in this paper were available at ESGF data portal (https://esgfdata.dkrz.de/search/cordex-dkrz/). The gridded $\left(0.5^{\circ} \times 0.5^{\circ}\right.$ resolution) decadal population and GDP data were available at Center for Global Environmental Research (CGER), National Institute for Environmental Studies (NIES), Japan (http://www.cger.nies.go.jp/gcp/population-and-gdp.html). We also acknowledge 
the India Meteorological Department (IMD) for the high-resolution $\left(0.5^{\circ} \times 0.5^{\circ}\right)$ daily gridded rainfall data sets over India. The first author acknowledges the financial support of the Department of Science and Technology (DST) for the INSPIRE Fellowship, international travel support from SERB (ITS/2018/005871), CSIR-4PI for their HPC support and ACSIR. The first author acknowledges CSTEP for their continuous support. Part of this work was also supported by the MoEFCC's NCAP project, Government of India (GAP-1009) and the National Monsoon Mission Phase-Il project of MoES (GAP1013).

\section{Declarations}

Not applicable

\section{Funding}

No funding

\section{Conflicts of interest/Competing interests}

The author(s) declare(s) that there is no conflict of interest.

\section{Author's contribution}

All authors contributed to the study conception and design. Material preparation, data collection and analysis were performed by C B Jayasankar under the supervision of K Rajendran and Sajani Surendran. The first draft of the manuscript was written by C B Jayasankar and all authors commented/edited on previous versions of the manuscript. All authors read and approved the final manuscript.

\section{Availability of data and material}

The CORDEX-SA simulations used in this paper were available at ESGF data portal (https://esgfdata.dkrz.de/search/cordex-dkrz/). The gridded decadal population and GDP data were available at Center for Global Environmental Research (CGER), National Institute for Environmental Studies (NIES), Japan (http://www.cger.nies.go.jp/gcp/population-and-gdp.html). All other datasets generated during and/or analyzed during the current study are available from the corresponding author on reasonable request.

\section{Code availability}

Not applicable

\section{Ethics approval}

The author(s) declare(s) no competing interests. 
Not applicable

\section{Consent for publication}

Not applicable

\section{References}

1. Almazroui M, Saeed S, Saeed F, Islam MN, Ismail M (2020) Projections of precipitation and temperature over the South Asian countries in CMIP6. Earth Systems Environment 4(2):297-320

2. Bhaskaran B, Jones RG, Murphy JM, Noguer M et al (1996) Simulations of the Indian summer monsoon using a nested regional climate model: Domain size experiments. Clim Dyn 12:573-587

3. Bruy'ere CL, Done JM, Holland GJ, Fredrick S (2014) Bias corrections of global models for regional climate simulations of high-impact weather. Clim Dyn 43(7-8):1847-1856

4. Choudhary A, Dimri AP, Maharana P (2018) Assessment of CORDEX-SA experiments in representing precipitation climatology of summer monsoon over India. Theoret Appl Climatol 134(1-2):283-307

5. Dash SK, Shekhar MS, Singh GP (2006) Simulation of Indian summer monsoon circulation and rainfall using RegCM3. Theoret Appl Climatol 86:161-172

6. Dash SK, Mishra SK, Pattnayak KC, Mamgain A, Mariotti L, Coppola E et al (2015) Projected seasonal mean summer monsoon over India and adjoining regions for the twenty-first century. Theoret Appl Climatol 122(3-4):581-593

7. Dickinson RE, Errico RM, Giorgi F, Bates GT (1989) A regional climate model for the western United States. Clim Change 15(3):383-422

8. Ebi KL, Hallegatte S, Kram T, Arnell NW, Carter TR, Edmonds J, Kriegler E, Mathur R, O’Neill BC, Riahi K et al (2014) A new scenario framework for climate change research: background, process, and future directions. Clim Change 122(3):363-372

9. Gadgil S (1995) Climate change and agriculture - an Indian perspective. Curr Sci 69(8):649-659

10. Gadgil S (2003) The Indian monsoon and its variability. Annu Rev Earth Planet Sci 31(1):429-467

11. Gadgil S, Gadgil S (2006) The Indian monsoon, GDP and agriculture. Economic and Political Weekly pp 4887-4895

12. Gadgil S, Sajani S (1998) Monsoon precipitation in the AMIP runs. Clim Dyn 14(9):659-689

13. Ghimire S, Choudhary A, Dimri AP (2018) Assessment of the performance of CORDEX-South Asia experiments for monsoonal precipitation over the Himalayan region during present climate: part I. Clim Dyn 50(7-8):2311-2334

14. Giorgi F, Marinucci MR (1996) An investigation of the sensitivity of simulated precipitation to model resolution and its implications for climate studies. Mon Weather Rev 124:148-166

15. Giorgi F, Marinucci MR, Visconti G (1990) Use of a limited-area model nested in a general circulation model for regional climate simulation over Europe. Journal of Geophysical Research: Atmospheres 
95(D11):18,413-418,431

16. Giorgi F, Jones C, Asrar GR et al (2009) Addressing climate information needs at the regional level: the CORDEX framework. World Meteorological Organization (WMO) Bulletin 58(3):175

17. Gu H, Wang G, Yu Z, Mei R (2012) Assessing future climate changes and extreme indicators in east and south Asia using the RegCM4 regional climate model. Clim Change 114(2):301-317

18. Guhathakurta P, Rajeevan M (2007) Trends in the rainfall pattern over India. Int J Climatol 28(11):1453-1469

19. Gusain A, Ghosh S, Karmakar S (2020) Added value of CMIP6 over CMIP5 models in simulating Indian summer monsoon rainfall. Atmos Res 232:104680

20. Hassan M, Du P, Jia S, Iqbal W, Mahmood R, Ba W (2015) An assessment of the South Asian summer monsoon variability for present and future climatologies using a high resolution regional climate model (RegCM4.3) under the AR5 scenarios. Atmosphere 6(11):1833-1857

21. Huang F, Xu Z, Guo W (2019) Evaluating vector winds in the Asian-Australian monsoon region simulated by 37 CMIP5 models. Clim Dyn 53(1-2):491-507

22. IPCC (2013) Climate Change 2013: The physical science basis. Contribution of working group I to the Fifth assessment report of the intergovernmental panel on climate change [Stocker, T.F., and coauthors (eds.)]. Cambridge University Press, Cambridge, United Kingdom and New York, NY, USA p 1535

23. Jayasankar CB, Surendran S, Rajendran K (2015) Robust signals of future projections of Indian summer monsoon rainfall by IPCC AR5 climate models: Role of seasonal cycle and interannual variability. Geophys Res Lett 42(9):3513-3520

24. Jayasankar CB, Rajendran K, Surendran S (2018) Monsoon climate change projection for the orographic west coast of India using high-resolution nested dynamical downscaling model. Journal of Geophysical Research: Atmospheres 123(15):7821-7838

25. Jayasankar CB (2019) Reliable climate change projections over India through dynamical downscaling using very high-resolution regional climate model. PhD thesis, Academy of Scientific and Innovative Research p 261

26. Kitoh A, Ose T, Takayabu I (2016) Dynamical downscaling for climate projection with high-resolution MRI AGCM-RCM. Journal of the Meteorological Society of Japan Ser II 94:1-16

27. Kriegler E, O'Neill BC, Hallegatte S, Kram T, Lempert RJ, Moss RH, Wilbanks T (2012) The need for and use of socio-economic scenarios for climate change analysis: a new approach based on shared socio-economic pathways. Glob Environ Change 22:807-822

28. Krishna Kumar K, Rupa Kumar K, Ashrit R, Deshpande N, Hansen JW (2004) Climate impacts on Indian agriculture. Int J Climatol 24(11):1375-1393

29. Kumar KR, Sahai AK, Kumar KK, Patwardhan SK, Mishra PK et al (2006) High-resolution climate change scenarios for India for the 21st century. Curr Sci 90(3):334-345 
30. Lo JCF, Yang ZL, Pielke Sr RA (2008) Assessment of three dynamical climate downscaling methods using the weather research and forecasting (WRF) model. Journal of Geophysical Research: Atmospheres 113(D9)

31. Miguez-Macho G, Stenchikov GL, Robock A (2004) Spectral nudging to eliminate the effects of domain position and geometry in regional climate model simulations. Journal of Geophysical Research: Atmospheres 109(D13)

32. Mishra V, Kumar D, Ganguly AR, Sanjay J, Mujumdar M, Krishnan R, Shah RD (2014) Reliability of regional and global climate models to simulate precipitation extremes over India. Journal of Geophysical Research: Atmospheres 119(15):9301-9323

33. Mishra SK, Sahany S, Salunke P, Kang IS, Jain S (2018) Fidelity of CMIP5 multi-model mean in assessing Indian monsoon simulations. npj Climate Atmospheric Science 1(1):1-8

34. Moon S, Ha KJ (2020) Future changes in monsoon duration and precipitation using CMIP6. npj Climate Atmospheric Science 3(1):1-7

35. Murakami D, Yamagata Y (2019) Estimation of gridded population and GDP scenarios with spatially explicit statistical downscaling. Sustainability 11(7):2106

36. O'Neill BC, Kriegler E, Riahi K, Ebi KL, Hallegatte S, Carter TR, Mathur R, van Vuuren DP (2014) A new scenario framework for climate change research: the concept of shared socioeconomic pathways. Clim Change 122(3):387-400

37. O’Neill BC, Kriegler E, Ebi KL, Kemp-Benedict E, Riahi K, Rothman DS, van Ruijven BJ, van Vuuren DP et al (2017) The roads ahead: Narratives for shared socioeconomic pathways describing world futures in the 21 st century. Glob Environ Change 42:169-180

38. Parthasarathy B, Munot A, Kothawale D (1994) All-India monthly and seasonal rainfall series: 18711993. Theoret Appl Climatol 49(4):217-224

39. Paul S, Ghosh S, Rajendran K, Murtugudde R (2018) Moisture supply from the western ghats forests to water deficit east coast of India. Geophys Res Lett 45(9):4337-4344

40. Rajeevan M, Bhate J, Kale J, Lal B (2006) High resolution daily gridded rainfall data for the Indian region: Analysis of break and active. Curr Sci 91(3):296-306

41. Rajendran K, Kitoh A, Srinivasan J, Mizuta R, Krishnan R (2012) Monsoon circulation interaction with western ghats orography under changing climate. Theoret Appl Climatol 110(4):555-571

42. Rajendran K, Sajani S, Jayasankar CB, Kitoh A (2013) How dependent is climate change projection of Indian summer monsoon rainfall and extreme events on model resolution? Current Science, pp 1409-1418

43. Rajendran K, Surendran S, Varghese SJ, Sathyanath A (2021) Simulation of Indian summer monsoon rainfall, interannual variability and teleconnections: Evaluation of CMIP6 models. Research Square, DOI:10.21203/rs.3.rs-242562/v1, https://www.researchsquare.com/article/rs-242562/v1

44. Rao YP (1976) Southwest monsoon. India Meteorological Department, New Delhi, p 376 
45. Ratnam JV, Giorgi F, Kaginalkar A, Cozzini S (2009) Simulation of the Indian monsoon using the RegCM3-ROMS regional coupled model. Clim Dyn 33:119-139

46. Sanjay J, Krishnan R, Shrestha AB, Rajbhandari R, Ren GY (2017a) Downscaled climate change projections for the Hindu Kush Himalayan region using CORDEX South Asia regional climate models. Advances in Climate Change Research 8(3):185-198

47. Sanjay J, Ramarao M, Mujumdar M, Krishnan R (2017b) Regional climate change scenarios. Chapter of book: Observed Climate Variability and Change over the Indian Region Editors: M N Rajeevan and Shailesh Nayak, Springer Geology pp 285-304, doi:10.1007/978-981-10-2531-0

48. Singh S, Ghosh S, Sahana A, Vittal H, Karmakar S (2017) Do dynamic regional models add value to the global model projections of. Indian monsoon? Climate Dynamics 48(3-4):1375-1397

49. Sperber KR, Annamalai H, Kang IS, Kitoh A, Moise A, Turner A, Wang B, Zhou T (2013) The Asian summer monsoon: an intercomparison of CMIP5 vs. CMIP3 simulations of the late 20th century. Clim Dyn 41(9-10):2711-2744

50. Suman M, Maity R (2020) Southward shift of precipitation extremes over south Asia: evidences from CORDEX data. Scientific reports 10(1):1-11

51. Trenberth KE, Dai A, Rasmussen RM, Parsons DB (2003) The changing character of precipitation. Bull Am Meteor Soc 84(9):1205-1218

52. Varghese SJ, Surendran S, Rajendran K, Kitoh A (2020) Future projections of Indian Summer Monsoon under multiple RCPs using a high resolution global climate model multiforcing ensemble simulations. Clim Dyn 54(3):1315-1328

53. Voldoire, A., Exarchou, E., Sanchez-Gomez, E., Demissie, T., Deppenmeier, A. L., Frauen,C., ... Traoré, A. K. (2019). Role of wind stress in driving SST biases in the Tropical Atlantic. Climate Dynamics, 53(5), 3481-3504

54. Wang Y, Leung LR, McGREGOR JL, Lee DK, Wang WC, Ding Y, Kimura F (2004) Regional climate modeling: progress, challenges, and prospects. Journal of the Meteorological Society of Japan Ser II 82(6):1599-1628

55. Wang, B., Biasutti, M., Byrne, M. P., Castro, C., Chang, C. P., Cook, K., ... Zhou,T. (2021) Monsoons climate change assessment. Bulletin of the American Meteorological Society, 102(1): E1-E19

56. Webster PJ, Magana VO, Palmer T, Shukla J, Tomas R, Yanai M, Yasunari T (1998) Monsoons: Processes, predictability, and the prospects for prediction. Journal of Geophysical Research: Oceans 103(C7):14,451-414,510

57. Wiebe K, Lotze-Campen H, Sands R, Tabeau A et al (2015) Climate change impacts on agriculture in 2050 under a range of plausible socioeconomic and emissions scenarios. Environmental Research Letters 10(8):085010

58. Xu Z, Yang ZL (2012) An improved dynamical downscaling method with GCM bias corrections and its validation with 30 years of climate simulations. J Clim 25(18):6271-6286

\section{Tables}


Table 1 Details of 14 CORDEX South Asia regional climate model experiments and their parent model horizontal resolution (ESGF data portal, https://esgf-data.dkrz.de/search/cordex-dkrz/)

\begin{tabular}{|c|c|c|c|c|}
\hline $\begin{array}{c}\text { Model } \\
\text { Abbreviation }\end{array}$ & $\begin{array}{l}\text { Regional Climate } \\
\text { Model (RCM) }\end{array}$ & $\begin{array}{c}\text { Driving } \\
\text { CMIP5 GCM }\end{array}$ & $\begin{array}{l}\text { Resolution of } \\
\text { Driving GCM }\end{array}$ & $\begin{array}{c}\text { Contributing } \\
\text { CORDEX-SA } \\
\text { Modelling Institute }\end{array}$ \\
\hline CNRM-RCA4 & \multirow{9}{*}{$\begin{array}{l}\text { Rossby Centre regional } \\
\text { atmospheric model } \\
\text { version } 4 \text { (RCA4; } \\
\text { Samuelsson et al., 2011) }\end{array}$} & CNRM-CM5 & $1.406 \times 1.406$ & \multirow{9}{*}{$\begin{array}{c}\text { Rossby Centre, } \\
\text { Swedish Meteorological } \\
\text { and Hydrological } \\
\text { Institute (SMHI), } \\
\text { Sweden }\end{array}$} \\
\hline CSIRO-RCA4 & & CSIRO-Mk3.6 & $1.875 \times 1.875$ & \\
\hline CanESM2-RCA4 & & CanESM2 & $2.8125 \times 2.8125$ & \\
\hline GFDL-RCA4 & & GFDL-ESM2M & $2.0 \times 2.5$ & \\
\hline HadGEM2-RCA4 & & HadGEM2-ES & $1.241 \times 1.875$ & \\
\hline IPSL-RCA4 & & IPSL-CM5A-MR & $1.258 \times 2.5$ & \\
\hline MIROC-RCA4 & & MIROC5 & $1.406 \times 1.406$ & \\
\hline MPI-RCA4 & & MPI-ESM-LR & $1.875 \times 1.875$ & \\
\hline NorESM1-RCA4 & & NorESM1-M & $1.875 \times 2.5$ & \\
\hline CSIRO-RegCM4 & \multirow{5}{*}{$\begin{array}{c}\text { The Abdus Salam Institutional } \\
\text { Centre for Theoretical } \\
\text { Physics (ICTP) Regional } \\
\text { Climate Model Version } 4 \\
\text { (RegCM; Giorgi et al., 2012) }\end{array}$} & CSIRO-Mk3.6 & $1.875 \times 1.875$ & \multirow{5}{*}{$\begin{array}{l}\text { Centre for Climate } \\
\text { Change Research (CCCR), } \\
\text { Indian Institute of Tropical } \\
\text { Meteorology (IITM), India }\end{array}$} \\
\hline CanESM2-RegCM4 & & CanESM2 & $2.8125 \times 2.8125$ & \\
\hline GFDL-RegCM4 & & GFDL-ESM2M & $2.0 \times 2.5$ & \\
\hline IPSL-RegCM4 & & IPSL-CM5A-LR & $1.875 \times 3.75$ & \\
\hline MPI-RegCM4 & & MPI-ESM-MR & $1.875 \times 1.875$ & \\
\hline
\end{tabular}

Table 2 The mean climatological JJAS rainfall bias and PCC for all India (Al), Core Monsoon Zone (CMZ) and Western Ghats (WG) of CCSM4-WRF, 14 CORDEX-SA RCMs and its MME against IMD observation. Low bias values and high PCCs are highlighted in red 


\begin{tabular}{|l|c|c|c|c|c|c|}
\hline \multirow{2}{*}{ Model } & \multicolumn{3}{|c|}{ Mean Rainfall Bias } & \multicolumn{2}{c|}{ Pattern Correlation Cocfficient } \\
\cline { 2 - 7 } & AI & CMZ & WG & AI & CMZ & WG \\
\hline \hline CCSM4-WRF & -0.871 & -0.984 & -0.975 & 0.783 & 0.816 & 0.755 \\
\hline CORDEX-MME & -1.269 & -0.795 & -5.767 & 0.717 & 0.839 & 0.581 \\
\hline CNRM-RCA4 & 0.195 & 1.590 & -2.879 & 0.626 & 0.630 & 0.748 \\
\hline CSIRO-RegCM4 & -2.894 & -3.001 & -7.831 & 0.576 & 0.869 & 0.337 \\
\hline CSIRO-RCA4 & -2.844 & -2.296 & -8.974 & 0.605 & $\mathbf{0 . 7 2 4}$ & 0.337 \\
\hline CanESM2-RegCM4 & 0.167 & 0.264 & -2.817 & 0.736 & 0.876 & 0.735 \\
\hline CanESM2-RCA4 & -3.361 & -3.327 & -10.657 & 0.570 & 0.699 & 0.074 \\
\hline GFDL-RegCM4 & -0.461 & -1.451 & -4.814 & 0.341 & 0.696 & 0.381 \\
\hline GFDL-RCA4 & 0.012 & 1.449 & -4.477 & 0.634 & 0.816 & 0.419 \\
\hline HadGEM2-RCA4 & -1.437 & -0.302 & -4.292 & 0.610 & $\mathbf{0 . 7 4 1}$ & 0.410 \\
\hline IPSL-RegCM4 & -0.754 & -0.878 & 3.426 & 0.425 & 0.684 & 0.737 \\
\hline IPSL-RCA4 & -2.268 & -1.695 & -7.062 & 0.648 & $\mathbf{0 . 7 9 9}$ & 0.288 \\
\hline MIIROC-RCA4 & -1.162 & -0.272 & -7.636 & 0.597 & 0.818 & 0.322 \\
\hline MPI-RegCM4 & -1.086 & -1.242 & -6.459 & 0.465 & 0.806 & 0.600 \\
\hline MPI-RCA4 & -0.609 & 0.389 & -6.714 & 0.621 & $\mathbf{0 . 7 8 9}$ & 0.540 \\
\hline NorESM1-RCA4 & -1.263 & -0.360 & -9.551 & 0.536 & $\mathbf{0 . 7 9 7}$ & -0.011 \\
\hline \hline
\end{tabular}

\section{Figures}




\section{JJAS Rainfall (mm/day)}

\section{IMD (Observation)}
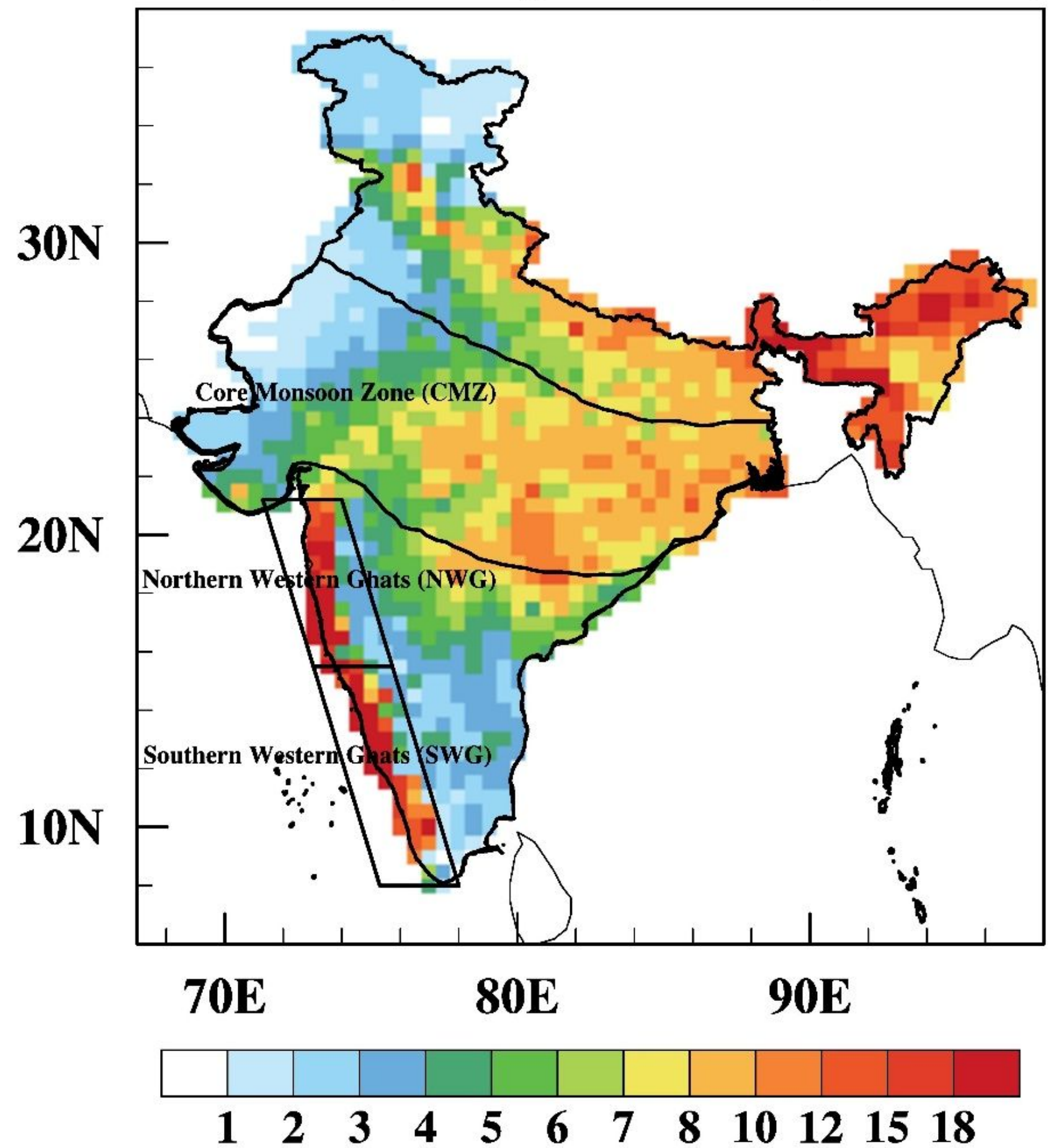

Figure 1

The 10-year (1981-1990) climatological mean summer monsoon (June to September) rainfall from IMD observation. The Western Ghats (WG, separated as southern and northern WG regions) and core monsoon zone (CMZ) are denoted. Note: The designations employed and the presentation of the material on this map do not imply the expression of any opinion whatsoever on the part of Research Square 
concerning the legal status of any country, territory, city or area or of its authorities, or concerning the delimitation of its frontiers or boundaries. This map has been provided by the authors.

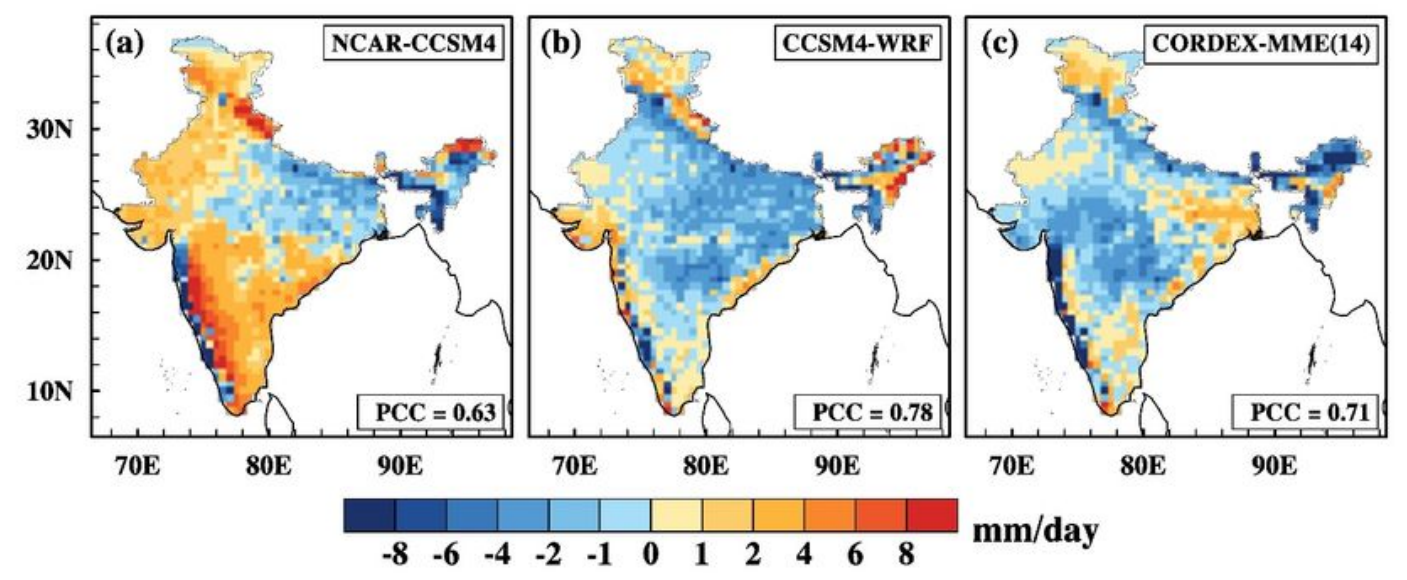

Figure 2

The climatological June to September (JJAS) rainfall bias of a) forcing GCM (NCAR-CCSM4), b) highresolution RCM (CCSM4-WRF) and c) MME of 14 CORDEX-SA RCMs (CORDEX-MME) with respect to IMD observation. Pattern correlation coefficient (PCC) with respect to IMD observation is given in inset. All the 
model simulation datasets were re-gridded to the IMD observation resolution (i.e. $0.5^{\circ} \times 0.5^{\circ}$ ). Note: The designations employed and the presentation of the material on this map do not imply the expression of any opinion whatsoever on the part of Research Square concerning the legal status of any country, territory, city or area or of its authorities, or concerning the delimitation of its frontiers or boundaries. This map has been provided by the authors.

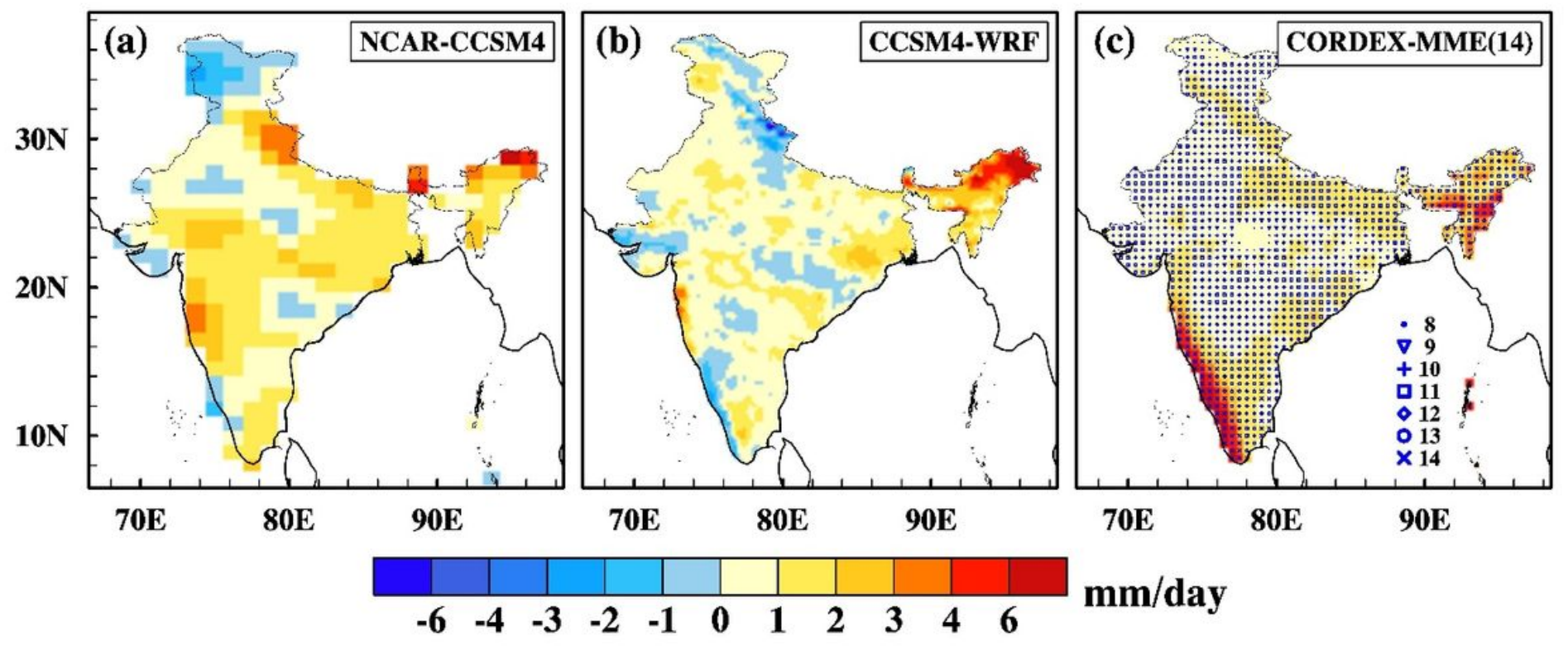

\section{Figure 3}

Projected change in climatological JJAS mean rainfall over India at the end of the 21st century (20902099) from a) NCAR-CCSM4, b) CCSM4-WRF and c) multi-model ensemble (MME) of 14 CORDEX-SA models under the RCP8.5 scenario. For the MME of 14 CORDEX-SA models, the model agreements in the sign of projected change at each grid points are shown with different symbols. Note: The designations employed and the presentation of the material on this map do not imply the expression of any opinion whatsoever on the part of Research Square concerning the legal status of any country, territory, city or area or of its authorities, or concerning the delimitation of its frontiers or boundaries. This map has been provided by the authors. 


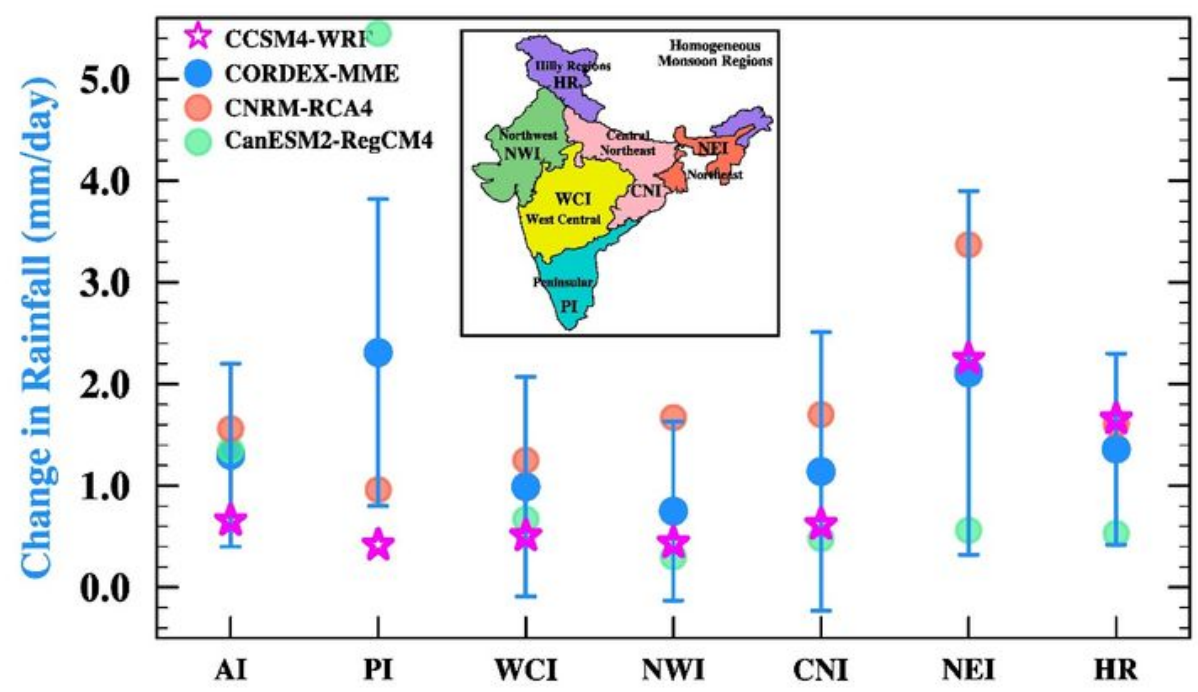

Figure 4

The quantification of projected Indian summer monsoon rainfall changes over all-India and at different homogeneous zones of India. Note: The designations employed and the presentation of the material on this map do not imply the expression of any opinion whatsoever on the part of Research Square concerning the legal status of any country, territory, city or area or of its authorities, or concerning the delimitation of its frontiers or boundaries. This map has been provided by the authors. 

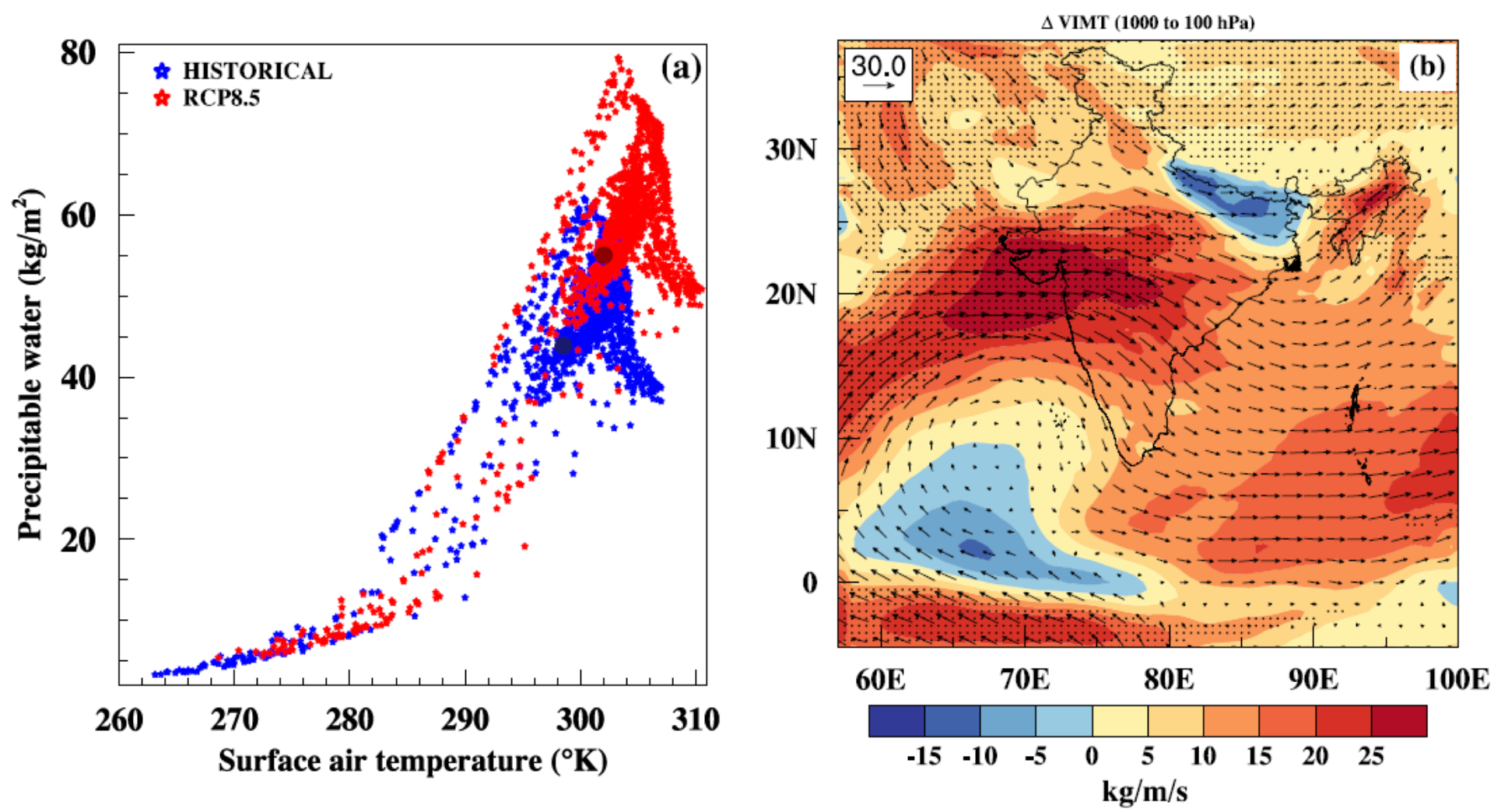

Figure 5

a) CCSM4-WRF simulated mean summer monsoon precipitable water $(\mathrm{kg} / \mathrm{m} 2)$ over Indian grid points is plotted against the corresponding surface air temperature $\left({ }^{\circ} \mathrm{K}\right)$ for historical and RCP8.5 scenarios. The filled circles represent the respective averaged values over India. b) Projected future changes in vertically integrated moisture transport (VIMT, integrated from 1000-hPa to 100-hPa) under RCP8.5 scenario with respect to the historical simulation. VIMT significant at $95 \%$ are stippled and vectors show direction of VIMT. Note: The designations employed and the presentation of the material on this map do not imply the expression of any opinion whatsoever on the part of Research Square concerning the legal status of any country, territory, city or area or of its authorities, or concerning the delimitation of its frontiers or boundaries. This map has been provided by the authors. 

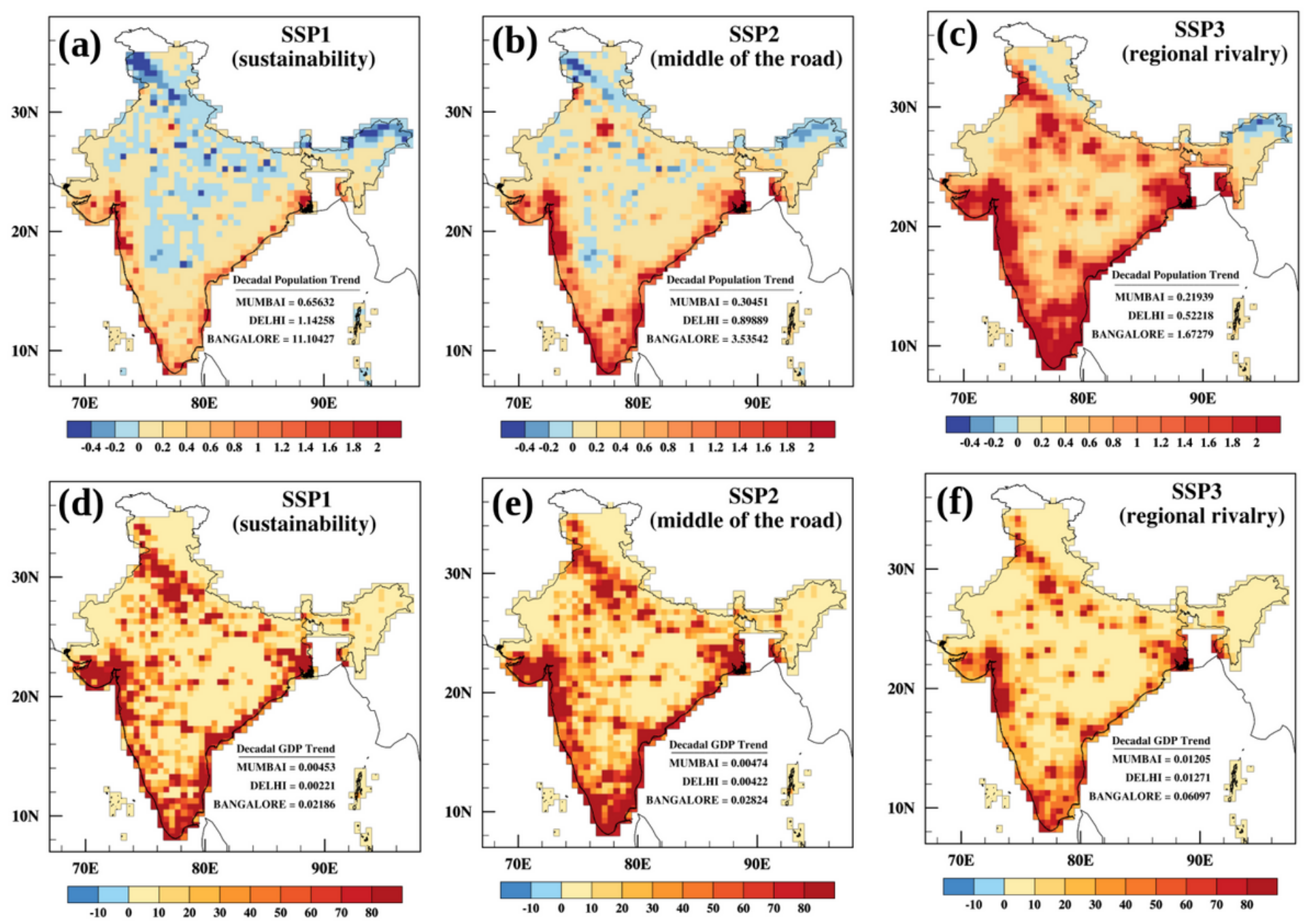

Figure 6

Projected change (2100-1990) in population density (in million) over India for the three SSPs is shown in the top panels (a-c). The projected change in the gross domestic product (GDP) in purchasing power parity (PPP), Billion USD in 2005 year rate is in the bottom panels (e-g). The decadal trend of GDP (million/decade) and population (PPP/decade) over three densely populated Indian cities (Mumbai, Delhi, and Bengaluru) is given in the inset. Note: The designations employed and the presentation of the material on this map do not imply the expression of any opinion whatsoever on the part of Research Square concerning the legal status of any country, territory, city or area or of its authorities, or concerning the delimitation of its frontiers or boundaries. This map has been provided by the authors.

\section{Supplementary Files}

This is a list of supplementary files associated with this preprint. Click to download.

- TAACSupplementaryMaterialRev.docx 